\title{
Research Paper: Gender Identification Based on the Parameters of the Sternum Bone in the Cadavers
}

\author{
Siamak Soltani' (D), Abbas Aghabiklooei ${ }^{1}$ (D), Maryam Ameri ${ }^{1}$, Azadeh Memarian1 $^{1}$ (D), Ali Nikanzad ${ }^{\text {* }}$
}

1. Forensic and Legal Medicine, Iran University of Medical Sciences, Tehran, Iran.

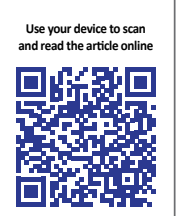

Crtation: Soltani S, Aghabiklooei A, Ameri M, Memarian A, Nikanzad A. Gender Identification Based on the Parameters of the Sternum Bone in the Cadavers. International Journal of Medical Toxicology and Forensic Medicine. 2020; $10(1): 26740$. https://doi.org/10.32598/ijmtfm.v10i1.26740

https://doi.org/10.32598/ijmtfm.v10i1.26740

Article info:

Received: 15 Aug 2019

First Revision: 20 Aug 2019

Accepted: 03 Sep 2019

Published: 03 Apr 2020

Keywords:

Gender, Sternum, Cadavers

\section{ABSTRACT}

Background: Identifying identity in the absence of large bones becomes more difficult and complicated; accordingly, it is highly beneficial to use the features of the sternum. The present study aimed to evaluate the dimensions of the sternum and its relation with gender in the Iranian population.

Methods: This cross-sectional study was conducted on 200 cadavers (100 men and 100 women). By performing an autopsy, the sternum bone was first cut in the midline using a vibrating saw, and the different dimensions were measured using a caliper.

Results: Among different dimensions related to the sternum, the mean length of manubrium, mesosternum, the largest width of manubrium, and the shortest width of manubrium were significantly higher in men compared to women. Regarding the value of each sternal diameter in discriminating male and female gender, the highest discriminative value was specified to the shortest width of manubrium (cutoff: 26.75 , sensitivity: $100 \%$, specificity: $84.0 \%$ ), followed by the length of sternebrae 1 (cutoff: 8.45 , sensitivity: $76.0 \%$, specificity: $21.0 \%$ ).

Conclusion: Measuring various indices of sternum bone, particularly the shortest width of the manubrium and the length of sternebrae 1 , leads to gender identity accurately.

\section{Introduction}

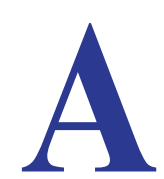

nthropometry defines the size, weight, and characteristics of the human body and its skeleton $[1,2]$. It is considered as a multipurpose technique for determining gender and is more accurately quoted by specific analysis. In addition, it can provide the standards of gender determination in different populations [3]. A favorite subject of legal anthropologists and archaeologists is de- termining the gender of bodies by their skeletal components [4]. Identifying the gender of unknown cadavers from the skeletal structure is much more complicated than studying a cadaver. In some situations, the remains of a deceased person have been found after death; these skeletal remains are often incomplete to help provide information on gender, age, race, stature, and death cause [5-7]. Gender determination is among the critical issues in forensic medicine [8]. Given the differences between the nations and their physical characteristics, it is nec- 
essary to perform specific examinations in each region. Gender determination using bone measurements is an effective method, i.e., less costly than other techniques, including Deoxyribonucleic Acid (DNA) and chromosome analysis.

Furthermore, it requires less time and implementation for personnel who do not have skeletal analyzes. In general, there are two methods for detecting gender from skeletal remains, including morphological and metric methods. The morphological approach is experimental and faster; however, it requires a skilled person to determine gender. Besides, the metric method is based on measurements and statistical techniques [11], which involves repetition for authentication [12]. Different parts of the human skeleton have been used to recognize gender by metric and nonmetric methods, including the shape and size of the legs, head, soles, long bones of the arm, and teeth [13]. When the skeleton of the body, especially the skull and the pelvis, is available, gender determination could be more reliable [14]. Identifying skeletal remains is among the forensic medicine problems [15]; it means finding a set of symptoms that leads to identifying one person from others [16]. One of the main issues in this respect is that in examining the identity of the skeletal remains, in cases where there are no significant bones, such as pelvic bones and skulls, the problem of identification becomes more complicated. In this case, using the characteristics of sternum bone will be very efficient. The present study aimed to evaluate the dimensions of the sternum and its relation to gender in the Iranian population.

\section{Materials and Methods}

This cross-sectional study was conducted on 200 cadavers (100 men and 100 women) referred to the Kahrizak Dissection hall from 2017 to 2018. Any evidence of pathological sternum, such as traumatic changes, degenerative, articular, or bone changes, or death of $>24$ hours was considered as the exclusion criteria. By performing an autopsy, the sternum bone was first cut in the midline using a vibrating saw. The surface of the bone was washed with water to sharpen the bone's circumference, the thickness of the bone, as well as the discrimination of manubrium, body, and xiphoid process. After determining the limits of different parts of the bone, various sternum landmarks, including the length of manubrium, width of manubrium, length and width of mesosternum, length of sternebrae 1 and sternbera 3, the largest and shortest width of manubrium, the ratio of the width of the sternebrae 1 to sternebrae 3 , and the ratio of the length of manubrium to mesosternum were determined using a caliper. These data were then compared between men and women. In this study, the sternum area was also calculated by the following formula: $\mathrm{SA}=[(\mathrm{ML}+\mathrm{SL})] \times(\mathrm{MW}+\mathrm{Sw} 1+\mathrm{SW} 3) / 3$, where $\mathrm{MW}$ was the width of manubrium, SL was the length of mesosternum, and ML was the length of the manubrium. Furthermore, the width of the manubrium was considered as the distance between the central zone of the articular surface at the first cartilage of the rib on both sides.

The obtained results were presented as Mean \pm SD for quantitative variables. Next, they were summarized by absolute frequencies and percentages for categorical variables. The normality of data was analyzed using the Kolmogorov-Smirnoff test. The quantitative variables were also compared with t-test or Mann-Whitney U test. The association between quantitative variables was assessed using Pearson's or Spearman's correlation tests. The collected data were analyzed in SPSS at the significance level of $\mathrm{P}<0.05$.

\section{Results}

Among different dimensions related to sternum, the mean length of manubrium, mesosternum, the largest width of manubrium, and the shortest width of manubrium were significantly higher in men, compared to women; however, no difference was revealed in other diameters, including the length of sternebrae 1 and sternbera 3 , the ratio of the length of sternebrae 1 to sternbera 3 , the sum of the length of manubrium and mesosternum, and the ratio of the length of manubrium to mesosternum (Table 1). The length and width of the manubrium were significantly associated with the length of mesosternum, the total length of sternum, the width of manubrium, as well as body weight and height. Moreover, the length of the mesosternum was directly associated with the length and width of manubrium, the total length of sternum, the largest and shortest width of manubrium, and body weight and height.

Regarding the value of each sternal diameter in gender determination (Table 2), the highest discriminative value belomged to the shortest width of manubrium (AUC $=0.94$, cutoff: 26.75 , sensitivity: $100 \%$, specificity: $84.0 \%$ ), followed by the length of sternebrae 1 (AUC $=0.42$, cutoff: 8.45 , sensitivity: $76.0 \%$, specificity: $21.0 \%$ ).

\section{Discussion}

Identifying identity in the absence of large bones becomes more difficult and complicated; accordingly, it 
Table 1. The sternum-related dimensions in men and women

\begin{tabular}{|c|c|c|c|}
\hline \multirow{2}{*}{ Dimension } & \multicolumn{2}{|c|}{ Mean $\pm S D$} & \multirow{2}{*}{$\mathbf{P}$} \\
\hline & Men & Women & \\
\hline The length of manubrium & $56.94 \pm 2.55$ & $52.81 \pm 1.12$ & $<0.001$ \\
\hline The width of manubrium & $34.87 \pm 1.64$ & $32.74 \pm 2.14$ & $<0.001$ \\
\hline The length of mesosternum & $141.74 \pm 0.79$ & $130.41 \pm 1.26$ & $<0.001$ \\
\hline The length of sternebrae 1 & $29.75 \pm 1.07$ & $29.96 \pm 0.68$ & 0.098 \\
\hline The length of sternebrae 3 & $42.71 \pm 1.21$ & $41.85 \pm 5.18$ & 0.123 \\
\hline The largest width of the manubrium & $44.49 \pm 1.94$ & $44.84 \pm 1.79$ & $<0.001$ \\
\hline The shortest width of the manubrium & $29.78 \pm 1.13$ & $24.44 \pm 2.28$ & $<0.001$ \\
\hline The length of sternebrae 1 to sternebrae 3 & $0.69 \pm 0.03$ & $0.79 \pm 0.68$ & 0.170 \\
\hline The total length of the manubrium and mesosternum & $269.16 \pm 26.92$ & $217.52 \pm 14.06$ & 0.050 \\
\hline The length of the manubrium to the mesosternum ratio & $0.40 \pm 0.02$ & $0.41 \pm 0.007$ & 0.060 \\
\hline
\end{tabular}

Table 2. The results of ROC curve analysis for discriminating genders

\begin{tabular}{|c|c|c|c|c|}
\hline Dimension & Cutoff & Sensitivity & Specificity & AUC \\
\hline The length of manubrium & 54.4 & 0.76 & 0.95 & 0.93 \\
\hline The width of manubrium & 34.15 & 72.73 & 0.73 & 0.78 \\
\hline The largest width of manubrium & 43.65 & 0.68 & 0.72 & 0.77 \\
\hline The shortest width of manubrium & 26.75 & 100 & 0.84 & 0.94 \\
\hline The length of sternebrae 1 & 8.45 & 0.76 & 0.21 & 0.42 \\
\hline The length of sternebrae 2 & 23.75 & 0.74 & 0.67 & 0.88 \\
\hline The length of sternebrae 3 & 41.15 & 0.95 & 0.11 & 0.52 \\
\hline The total length of sternum & 230.15 & 0.88 & 0.82 & 0.89 \\
\hline
\end{tabular}

is highly beneficial to use the features of the sternum. Thus, we aimed to determine the dimensions of the sternum and their relationship with gender in the Iranian population. We found a significantly higher mean length of manubrium, mesosternum, the largest width of manubrium, and the shortest width of manubrium in men, compared to women. To assess the value of each parameter for gender differentiation, the ROC curve was used, providing high sensitivity and specificity of the shortest width of the manubrium and the length of sternebrae 1 . There were the most useful dimensions of the sternum to discriminate genders. In other words, due to the sig- nificant differences in the dimensions of the sternum in various ethnicities, gender differentiation is impossible by examining all the parameters; therefore, there is no significant correlation between all of the parameters.

Additionally, the values of sternum-related dimensions are very different and heterogeneous in various populations. Torimitsu et al. in Japan indicated a diagnostic accuracy varying between $62.5 \%$ and $84 \%$ in identifying gender. The researchers reported that measuring sternal indices could be an effective method of gender identification among Japanese bodies; in many cases, it is bet- 
ter than other predictive factors, like the pelvis bone and skull [17]. Ekizoglu et al. conducted a study in Turkey [18]. They concluded that all sternal indices were higher men than women, and the sternal index was lower in men. In general, sensitivity, specificity, and the precision of gender differentiation by sternal indices were $75.9 \%$, $87.6 \%$, and $80 \%$, respectively [18]. Another study by Franklin et al. in the United States, in 2012, indicated that the variance of the measurements between the genders was between $9.8 \%$ and $47.4 \%$ [19]. In general, the diagnostic accuracy of sternal landmarks for gender differentiation was between $72.2 \%$ and $84.5 \%$, all of which had an error of $<5 \%$. In their study, the mesosternum length had the highest accuracy in gender estimation [19]. Chandrakanth et al. argued that all three parameters of manubrium length, mesosternum length, and total manubrium and mesosternum length were significantly higher in men than women [20]. In the defemination of gender using sternal parameters in predicting modeling, the predictive power ranged between $67.5 \%$ for sternebrae 3 and $74.4 \%$ for the total length of manubrium and mesosternum [20]. Macaluso et al. also found that the highest value for discriminating genders was related to the sternebrae 3 parameters in the Spanish population [21]. Although all the studies referred to the indicators of the sternum for the precise determination of gender, the diagnostic accuracy of these markers was quite different in various societies.

In our study, the length of manubrium had a high value for discriminating genders; thus, the sternal lengths of males were also longer than those of females. According to Yonguc et al. [22], all measured sternal lengths were greater in males compared to females. In this regard, the length of the manubrium had the highest correlation coefficient in both genders. The literature suggests that sternal lengths are longer in males than females [23-26]. In our study, the body of manubrium (mesosternum) could also be predictive for the male gender. According to a defined index named the Hyrtl's law, the ratio of Manubrium to Body (M/B) index exceeds 50 in females and is $<50$ in males [27]; therefore, the body of sternum plays a critical role in discriminating genders. However, in some societies, Hyrtl's law could not be discriminative for gender identity. As per Ramadan's study on the Turkish population [25], Hyrtl's law was inapplicable to Turkish males; therefore, the body or manubrium might not predict gender in that population.

Similarly, in our study on Iranians, the ratio of the length of manubrium to mesosternum could not discriminate males from females. In addition, in our study, the length of sternebrae 1 and sternbera 3 were not predicting pa- rameters for gender identification. As contrarily indicated by Atal et al., the width of the first sternebrae and third sternebrae were significantly higher in males compared to females. According to Jit et al. [27], the mean width of the first sternebrae was $27.4 \mathrm{~mm}$ for males and 24.3 $\mathrm{mm}$ for females. Dahiphale et al. [28] found that the average widths of first sternebrae were $27.1 \mathrm{~mm}$ for males and $24.4 \mathrm{~mm}$ for a female with a significant difference. The length of sternbera 3 was also predictive for gender identification in both Jit and Dahiphale studies [27, 28]. Thus, the parameters of the length of sternebrae 1 and sternbera 3 or their ratio cannot apply for discriminating genders in the Iranian population.

\section{Conclusion}

In conclusion, a collection of sternum-related parameters, including the mean length of manubrium, mesosternum, the largest width of manubrium, and the shortest width of manubrium, were significantly higher in men than women; thus, they play a crucial role in gender identity among Iranian population.

The present study findings indicated that measuring various indices of sternum bone in the studied samples could accurately estimate the gender of cadavers. Assessing the dimensions of sternum could replace the indices related to long bones for gender identity.

\section{Ethical Considerations}

\section{Compliance with ethical guidelines}

All ethical principles were considered in this article. The participants were informed about the purpose of the research and its implementation stages; they were also assured about the confidentiality of their information; Moreover, They were allowed to leave the study whenever they wish, and if desired, the results of the research would be available to them.

\section{Funding}

This research did not receive any specific grant from funding agencies in the public, commercial, or not-forprofit sectors.

\section{Author's contributions}

All authors contributed equally in preparing all parts of the research. 


\section{Conflict of interest}

The authors declared no conflict of interest.

\section{References}

[1] Ahmed AA. Estimation of sex from the upper limb measurements of Sudanese adults. Journal of Forensic and Legal Medicine. 2013; 20(8):1041-7. [DOI:10.1016/j.jflm.2013.09.031] [PMID]

[2] Mohammad YA. Anthropometric characteristics of the hand based on laterality and sex among Jordanian. International Journal of Industrial Ergonomics. 2005; 35(8):747-54. [DOI:10.1016/j.ergon.2004.11.005]

[3] Charisi D, Eliopoulos C, Vanna V, Koilias CG, Manolis SK. Sexual dimorphism of the arm bones in a modern Greek population. Journal of Forensic Sciences. 2011; 56(1):10-8. [DOI:10.1111/j.1556-4029.2010.01538.x] [PMID]

[4] Krishan K, Kanchan T, Asha N, Kaur S, Chatterjee PM, Singh $B$. Estimation of sex from index and ring finger in a North Indian population. Journal of Forensic and Legal Medicine. 2013; 20(5):471-9. [DOI:10.1016/j.jflm.2013.03.004] [PMID]

[5] Kanchan T, Krishan K. Anthropometry of hand in sex determination of dismembered remains - A review of literature. Journal of Forensic and Legal Medicine. 2011; 18(1):14-7. [DOI:10.1016/j.jlm.2010.11.013] [PMID]

[6] Khanpetch P, Prasitwattanseree S, Case DT, Mahakkanukrauh $P$. Determination of sex from the metacarpals in a Thai population. Forensic Science International. 2012; 217(13):229.e1-8. [DOI:10.1016/j.forsciint.2011.10.044] [PMID]

[7] Zech W-D, Hatch G, Siegenthaler L, Thali MJ, Lösch S. Sex determination from os sacrum by postmortem CT. Forensic Science International. 2012; 221(1-3):39-43. [DOI:10.1016/j. forsciint.2012.03.022] [PMID]

[8] Mostafa EM, El-Elemi AH, El-Beblawy MA, Dawood AEWA. Adult sex identification using digital radiographs of the proximal epiphysis of the femur at Suez Canal University Hospital in Ismailia, Egypt. Egyptian Journal of Forensic Sciences. 2012; 2(3):81-8. [DOI:10.1016/j.ejfs.2012.03.001]

[9] Gharedaghi J, Kiani M, Khazali P, Ghoreishi M. Servey of sternum and its relation to sex, age and height dimensions of the Iranian population. Iranian Journal of Forensic Medicine. 2005; 12(1):35-9

[10] Akhlaghi M, Bakhtavar KH, Allahyar Parsa V, Ali RN, Razavi Nouri A, Mehdizadeh F, M, Vasheghani Farahani M, et al. Sexing based on measurements of the femoral head parameters on pelvic radiographs. Journal of Forensic and Legal Medicine. 2014; 23:70-5. [DOI:10.1016/j.jflm.2014.01.004] [PMID]

[11] Gonzalez PN, Bernal V, Perez SI. Geometric morphometric approach to sex estimation of human pelvis. Forensic Science International. 2009; 189(1-3):68-74. [DOI:10.1016/j.forsciint.2009.04.012] [PMID]
[12] Hayashizaki Y, Usui A, Hosokai Y, Sakai J, Funayama M. Sex determination of the pelvis using fourier analysis of postmortem CT images. Forensic Science International. 2015; 246:122.e1-9. [DOI:10.1016/j.forsciint.2014.10.008] [PMID]

[13] Asala SA. The efficiency of the demarking point of the femoral head as a sex determining parameter. Forensic Science International. 2002; 127(1-2):114-8. [DOI:10.1016/S03790738(02)00114-7]

[14] Jowaheer V, Agnihotri AK. Sex identification on the basis of hand and foot measurements in Indo-Mauritian population-a model based approach. Journal of Forensic and Legal Medicine. 2011; 18(4):173-6. [DOI:10.1016/j.jflm.2011.02.007] [PMID]

[15] Clavero A, Salicrú M, Turbón D. Sex prediction from the femur and hip bone using a sample of CT images from a Spanish population. International Journal of Legal Medicine. 2015; 129(2):373-83. [DOI:10.1007/s00414-014-1069-y] [PMID]

[16] Yoshino M, Miyasaka S, Sato H, Seta S. Classification system of frontal sinus patterns by radiography. Its application to identification of unknown skeletal remains. Forensic Science International. 1987; 34(4):289-99. [DOI:10.1016/03790738(87)90041-7]

[17] Torimitsu S, Makino Y, Saitoh H, Sakuma A, Ishii N, Inokuchi G, et al. Estimation of sex in Japanese cadavers based on sternal measurements using multidetector computed tomography. Legal Medicine. 2015; 17(4):226-31. [DOI:10.1016/j. legalmed.2015.01.003] [PMID]

[18] Ekizoglu O, Hocaoglu E, Inci E, Bilgili MG, Solmaz D, Erdil $\mathrm{I}$, et al. Sex estimation from sternal measurements using multidetector computed tomography. Medicine. 2014; 93(27):e240 [DOI:10.1097/MD.0000000000000240] [PMID] [PMCID]

[19] Franklin D, Cardini A, Flavel A, Kuliukas A. Estimation of sex from cranial measurements in a Western Australian population. Forensic Science International. 2013; 229(1-3):158.e1e8. [DOI:10.1016/j.forsciint.2013.03.005] [PMID]

[20] Chandrakanth HV, Kanchan T, Krishan K. Osteometric analysis for sexing of modern sternum - An autopsy study from South India. Legal Medicine. 2014; 16(6):350-6. [DOI:10.1016/j.legalmed.2014.07.007] [PMID]

[21] Macaluso PJ Jr, Lucena J. Estimation of sex from sternal dimensions derived from chest plate radiographs in contemporary Spaniards. International Journal of Legal Medicine. 2014 128(2):389-95. [DOI:10.1007/s00414-013-0910-z] [PMID]

[22] Yonguc GN, Kurtulus A, Bayazit O, Adiguzel E, Unal I, Demir S, et al Estimation of stature and sex from sternal lengths: An autopsy study. Anatomical Science International. 2015; 90(2):89-96. [DOI:10.1007/s12565-014-0235-0] [PMID]

[23] Stewart JH, McCormick WF. The gender predictive value of sternal length. The American Journal of Forensic Medicine and Pathology. 1983; 4(3):217-20. [DOI:10.1097/00000433198309000-00007] [PMID]

[24] Hunnargi SA, Menezes RG, Kanchan T, Lobo SW, Binu VS, Uysal S, et al. Sexual dimorphism of the human sternum in a Maharashtrian population of India: A morphometric analysis. Legal Medicine. 2008; 10(1):6-10. [DOI:10.1016/j.legalmed.2007.05.011] [PMID]

[25] Ramadan SU, Turkmen N, Dolgun NA, Gokharman D, Menezes RG, Kacar M, et al. Sex determination from meas- 
urements of the sternum and fourth rib using multislice computed tomography of the chest. Forensic Science International. 2010; 15;197(1-3):120.e1-5. [DOI:10.1016/j.forsciint.2009.12.049] [PMID]

[26] Singh J, Pathak RK, Chavali KH. Skeletal height estimation from regression analysis of sternal lengths in a Northwest Indian population of Chandigarh region: A postmortem study. Forensic Science International. 2011; 20;206(1-3):211.e1-8. [DOI:10.1016/j.forsciint.2010.08.023] [PMID]

[27] Jit I, Jhingan V, Kulkarni M. Sexing the human sternum. American Journal of Physical Anthropology. 1980; 53(2):21724. [DOI:10.1002/ajpa.1330530206] [PMID]

[28] Dahiphale VP, Baheete BH, Kamkhedkar SG. Sexing the human sternum in Marathwada Region. Journal of the Anatomical Society of India. 2002; 51(2):162-7. 